\title{
Matched control study of visual outcomes after arteriovenous sheathotomy for branch retinal vein occlusion
}

This article was published in the following Dove Press journal:

Clinical Ophthalmology

26 February 2014

Number of times this article has been viewed

\author{
Shin Yamane' \\ Motohiro Kamei ${ }^{2}$ \\ Susumu Sakimoto ${ }^{2}$ \\ Maiko Inoue' \\ Akira Arakawa' \\ Mihoko Suzuki² \\ Nagakazu Matsumura ${ }^{2}$ \\ Kazuaki Kadonosono' \\ 'Department of Ophthalmology, \\ Yokohama City University Medical \\ Center, Yokohama, ${ }^{2}$ Department of \\ Ophthalmology, Osaka University \\ Graduate School of Medicine, \\ Osaka, Japan
}

Background: The purpose of this study was to evaluate visual outcomes of arteriovenous sheathotomy for macular edema due to branch retinal vein occlusion (BRVO).

Methods: The medical records of 45 eyes from 45 patients who had undergone vitrectomy surgery with arteriovenous sheathotomy for BRVO were studied. Forty-five eyes of 45 patients with a BRVO but without intervention were studied as the control group. The best-corrected visual acuity and central macular thickness were compared between the two groups at baseline and at 1, 3, 6, and 12 months postoperatively.

Results: Improvement of best-corrected visual acuity was 0.42 logarithm of the minimum angle of resolution (logMAR) units in the sheathotomy group and $0.22 \log$ MAR units in the control group $(P=0.007)$. The mean postoperative central macular thickness was significantly thinner in the sheathotomy group at 1 month $(P=0.01)$, but not at 3,6 , and 12 months $(P=0.75$, $P=0.81$, and $P=0.46$, respectively). Improvement of best-corrected visual acuity at 12 months was significantly correlated with baseline best-corrected visual acuity, age, duration of symptoms, and sheathotomy $(P<0.05)$.

Conclusion: Arteriovenous sheathotomy for BRVO improves best-corrected visual acuity significantly more than the natural course of the BRVO disease process.

Keywords: branch retinal vein occlusion, sheathotomy, macular edema, vitrectomy, observation

\section{Introduction}

A branch retinal vein occlusion (BRVO) is a relatively common retinal vascular disorder, and results in a severe and irreversible decrease in best-corrected visual acuity (BCVA) due to persistent macular edema. ${ }^{1-3}$ The BRVO usually occurs at an arteriovenous crossing where an artery and vein share a common adventitial sheath. ${ }^{4}$ The thickened and rigid arteriosclerotic arterial wall can compress the vein, causing turbulence of blood flow. The turbulence results in injury of the vascular endothelium and secondary thrombosis. ${ }^{5,6}$ Decompression of the artery at the arteriovenous crossing has been considered to be effective in improving retinal blood flow and resolving the mechanism causing the turbulence.

Osterloh and Charles were the first to report a surgical procedure for decompressing the arteriovenous crossing in $1988 .^{7}$ Since then, several groups have reported good results after arteriovenous sheathotomy in managing macular edema due to a BRVO. ${ }^{8-15}$ However, some reports have stated that the effectiveness of arteriovenous sheathotomy is still uncertain. ${ }^{16-22}$
4-57 Urafune-cho, Minami-ku, Yokohama, Kanagawa 232-0024, Japan

Tel +8I4526I 5656

Fax +8I452538490

Email shinyama@yokohama-cu.ac.jp 
Considering the mechanism of vein occlusion, arteriovenous sheathotomy would appear to be a rational treatment for BRVO. However, the natural course of BRVO can be relatively good in some eyes, and thus to determine the efficacy of arteriovenous sheathotomy, an appropriate untreated control group must be used. Only three studies have demonstrated the effectiveness of arteriovenous sheathotomy compared with the natural course of BRVO. ${ }^{10,14,22}$

Thus, the purpose of this study was to determine the efficacy and safety of arteriovenous sheathotomy for macular edema secondary to BRVO. To accomplish this, we compared the visual and anatomical outcomes of arteriovenous sheathotomy with outcomes after the natural course of BRVO in a control group.

\section{Materials and methods}

This was a retrospective, consecutive, matched, case control study of eyes undergoing arteriovenous sheathotomy for macular edema secondary to BRVO. The surgeries were performed at the Yokohama City University Medical Center and the Osaka University Hospital between January 2005 and December 2010. All patients received complete information about the natural course of BRVO and advantages and disadvantages of the treatments available and chose the treatment. An informed consent was obtained from all patients who opted to undergo arteriovenous sheathotomy. Patients with BRVO who did not have surgical intervention were followed as controls to determine the natural course of the disease process.

The exclusion criteria were age $<45$ or $>75$ years, BCVA $>20 / 40$, vein lying over the artery at the arteriovenous crossing, presence of collateral vessels, central macular thickness $<350 \mu \mathrm{m}$, follow-up period $<12$ months, prior laser photocoagulation, intravitreal injection of triamcinolone acetonide or anti-vascular endothelial growth factor therapy, prior ocular surgery except for cataract surgery, moderate or severe cataract that could cause vision decrease, and glaucoma, diabetic retinopathy, or any other disease that could cause vision reduction.

The study protocol was approved by the institutional review committee at Yokohama City University Medical Center and Osaka University Hospital, and the procedures used conformed to the tenets of the Declaration of Helsinki.

All patients underwent a standard ophthalmologic examination, including measurements of BCVA with a Landolt chart at $5 \mathrm{~m}$, slit-lamp examination, measurement of intraocular pressure, and dilated indirect slit-lamp biomicroscopy at all visits. The central macular thickness was measured by optical coherence tomography (Cirrus high-definition OCT;
Carl Zeiss, Dublin, CA, USA) using the macular thickness map program for the central $1 \mathrm{~mm}$.

The surgery consisted of 25-gauge microincision vitrectomy (CONSTELLATION ${ }^{\circledR}$ Vision System; Alcon Laboratories Inc., Fort Worth, Texas, USA) under local anesthesia. After removal of the posterior hyaloid membrane, the internal limiting membrane was removed at the macular area and at the site of arteriovenous crossing. The sheath over the arteriovenous crossing was incised with a modified 25-gauge microvitreoretinal blade that was bent at the tip. The incision separated the overlying artery from the vein. A complete arteriovenous dissection was confirmed by lifting the artery away from the underlying vein. Combined cataract surgery was performed prior to vitrectomy in 34 cases aged $>55$ years.

The mean BCVA was compared between the two groups preoperatively and at 1, 3, 6, and 12 months postoperatively. Multiple regression analyses were used to determine correlations between improvement in BCVA and baseline age, sex, BCVA, central macular thickness, duration of symptoms and signs, and combined sheathotomy and cataract surgery. Intraoperative and postoperative complications were recorded.

Statistical analysis was performed using Statistical Package for the Social Sciences version 17 software (IBM, Armonk, New York, USA). The decimal BCVA was converted to the logarithm of the minimum angle of resolution (logMAR), and significant differences in BCVA between the two groups were determined using the Mann-Whitney $U$ test. The Wilcoxon signed rank test was used to determine the significance of any association between preoperative and postoperative visual acuity and retinal thickness within the groups. An improvement or worsening of BCVA was defined as changes greater or less than $0.2 \log$ MAR units. The ratio of BCVA improvement, worsening, or unchanged was compared between the two groups using the chi-squared test. A $P$-value $<0.05$ was considered to be statistically significant.

\section{Results}

The medical records of 90 eyes from 90 patients with a BRVO were studied. Of these 90 eyes, 45 underwent arteriovenous sheathotomy (sheathotomy group) and 45 were followed without surgery (control group). No significant difference except for duration of symptoms was found in patient demographics between the two groups (Table 1). Arteriovenous sheathotomy was accomplished successfully in all eyes using a 25-gauge vitrectomy system. Fluid-air exchange was not performed in any of the eyes. Combined cataract surgery was performed in 34 of the $45(75.6 \%)$ eyes. No serious intraoperative complications, such as retinal detachment or choroidal hemorrhage, occurred except for mild hemorrhage at the arteriovenous crossing site. 
Table I Baseline characteristics

\begin{tabular}{llll}
\hline & Sheathotomy & Control & P-value \\
\hline Number of eyes (patients) & $45(45)$ & $45(45)$ & \\
Age (mean \pm SD, years) & $65.3 \pm 6.4$ & $67.2 \pm 7.2$ & $0.15^{*}$ \\
Sex (male/female) & $24 / 21$ & $21 / 24$ & $0.67^{\dagger}$ \\
$\begin{array}{l}\text { Estimated duration of } \\
\text { symptoms (months) }\end{array}$ & $4.1 \pm 2.4$ & $2.2 \pm 2.6$ & $<0.0 I^{*}$ \\
Baseline BCVA (mean $\pm S D)$ & $0.63 \pm 0.26$ & $0.62 \pm 0.26$ & $0.73^{*}$ \\
Foveal thickness $(\mu \mathrm{m})$ & $570.2 \pm 199.6$ & $578.3 \pm 259.1$ & \\
\hline
\end{tabular}

Notes: *Mann-Whitney $U$ test. Baseline BCVA in logMAR units; ${ }^{\dagger}$ Fisher exact probability test.

Abbreviations: SD, standard deviation; BCVA, best-corrected visual acuity; logMAR, logarithm of the minimum angle of resolution

Hemorrhage at the arteriovenous crossing site was seen in 11 of the $45(24.4 \%)$ eyes and stopped spontaneously within a few minutes. No vitreous hemorrhage, retinal detachment, endophthalmitis, or iris neovascularization was seen during follow-up period in either group.

In the sheathotomy group, mean preoperative BCVA was $0.63 \log$ MAR units, and improved to $0.41 \log$ MAR units at 1 month, $0.32 \log$ MAR units at 3 months, $0.25 \log$ MAR units at 6 months, and $0.22 \log$ MAR units at 12 months postoperatively (Figure 1). Mean postoperative BCVA was significantly better than preoperative BCVA at all times $(P<0.001)$. In the control group, mean BCVA was $0.62 \log$ MAR units at baseline, $0.52 \log$ MAR units at 1 month, $0.44 \log$ MAR units at 3 months, $0.43 \log$ MAR units at 6 months, and 0.40 $\log$ MAR units at 12 months postoperatively (Figure 1). Mean BCVA were significantly better than baseline at $1,3,6$, and 12 months $(P<0.05)$.

BCVA in the sheathotomy group was significantly better than in the control group at 6 and 12 months postoperatively
$(P<0.05$; Figure 1). Mean improvement in BCVA was $0.42 \log$ MAR units in the sheathotomy group and $0.22 \log M A R$ units in the control group $(P=0.007)$. The ratio of BCVA improvement $>0.2 \log$ MAR units, worsening $>0.2 \log$ MAR units, or unchanged from baseline to 12 months was significantly different between the sheathotomy and control groups ( $P=0.004$, chi-squared test; Figure 2).

Mean baseline central macular thickness was $570.2 \mu \mathrm{m}$ in the sheathotomy group and $578.3 \mu \mathrm{m}$ in the control group $(P=0.99)$. Mean postoperative central macular thickness was significantly decreased from the baseline thickness in both groups at all times ( $P<0.05$; Figure 3$)$. Mean postoperative central macular thickness was significantly narrower in the sheathotomy group than in the control group at 1 month $(P=0.01)$, but not at 3,6 , or 12 months $(P=0.75, P=0.81$, and $P=0.46$, respectively).

The results of the multiple regression analyses are shown in Table 2. Improvement in visual acuity was significantly better in eyes with lower baseline BCVA, younger age, and shorter duration of symptoms and signs, and in eyes that had undergone sheathotomy $(P<0.05)$. However, correlations between improvement in visual acuity and sex, central macular thickness, and combined cataract surgery were not significant.

\section{Discussion}

Our results show that arteriovenous sheathotomy for BRVO improved BCVA significantly at 6 and 12 months after surgery. Although improvement of macular edema and visual acuity can occur spontaneously during the natural course of BRVO, our findings show that arteriovenous sheathotomy

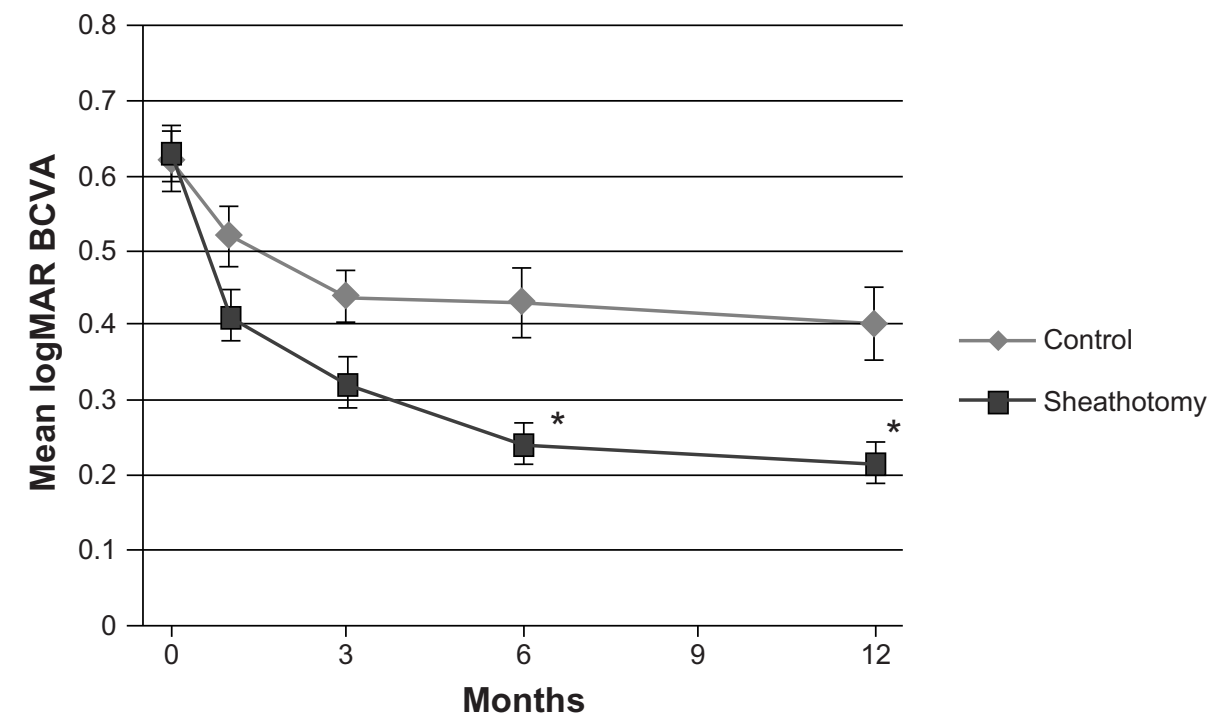

Figure I Changes in mean BCVA at baseline and at I, 3, 6, and 12 months. ${ }^{*} P<0.05$, Mann-Whitney $U$ test. Abbreviations: BCVA, best-corrected visual acuity; logMAR, logarithm of the minimum angle of resolution. 


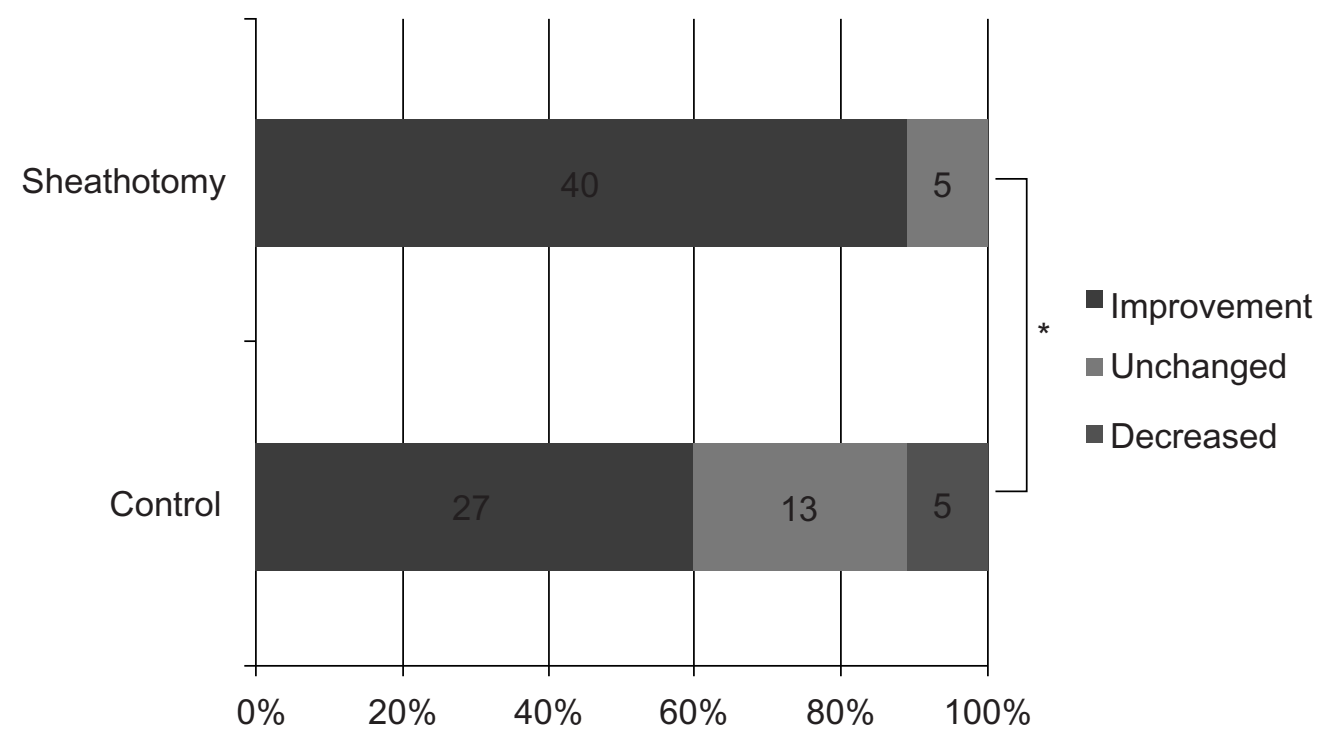

Figure 2 Ratio of changes in BCVA at 12 months. Improvement was defined as an increase of $>0.2 \log M A R$ units, while a decrease was defined as a reduction of $>0.2$ logMAR units. $* P<0.05$, chi-squared test.

Abbreviations: BCVA, best-corrected visual acuity; logMAR, logarithm of the minimum angle of resolution.

led to significantly better BCVA than that observed in the control group without surgery.

Since the first report by Osterloh and Charles, several authors have performed arteriovenous sheathotomy to treat macular edema due to BRVO, although only a few studies compared their results with the natural course of BRVO. ${ }^{8-22}$ The results of a matched control study comparing the effects of arteriovenous sheathotomy with that in a matched control group of observation alone and laser-treated eyes demonstrated better visual outcomes in an arteriovenous sheathotomy group than in a matched control group. ${ }^{14}$ However, the sample size of this study was 20 surgical, ten observation only, and ten laser-treated eyes. In another study, eight natural course eyes had better visual outcomes than eight arteriovenous sheathotomy eyes at 12 and 36 months. ${ }^{22}$ Another study reported better visual outcomes for 43 arteriovenous sheathotomy eyes than in 25 observation only eyes. ${ }^{10}$ Unfortunately, the follow-up period was only 6 weeks in this study.

We studied 45 surgical and 45 observation only eyes with a 12-month follow-up. Eyes with a vein lying over the artery at the arteriovenous crossing and collateral vessels were excluded, considering the mechanism of BRVO and arteriovenous sheathotomy. In addition, multiple regression

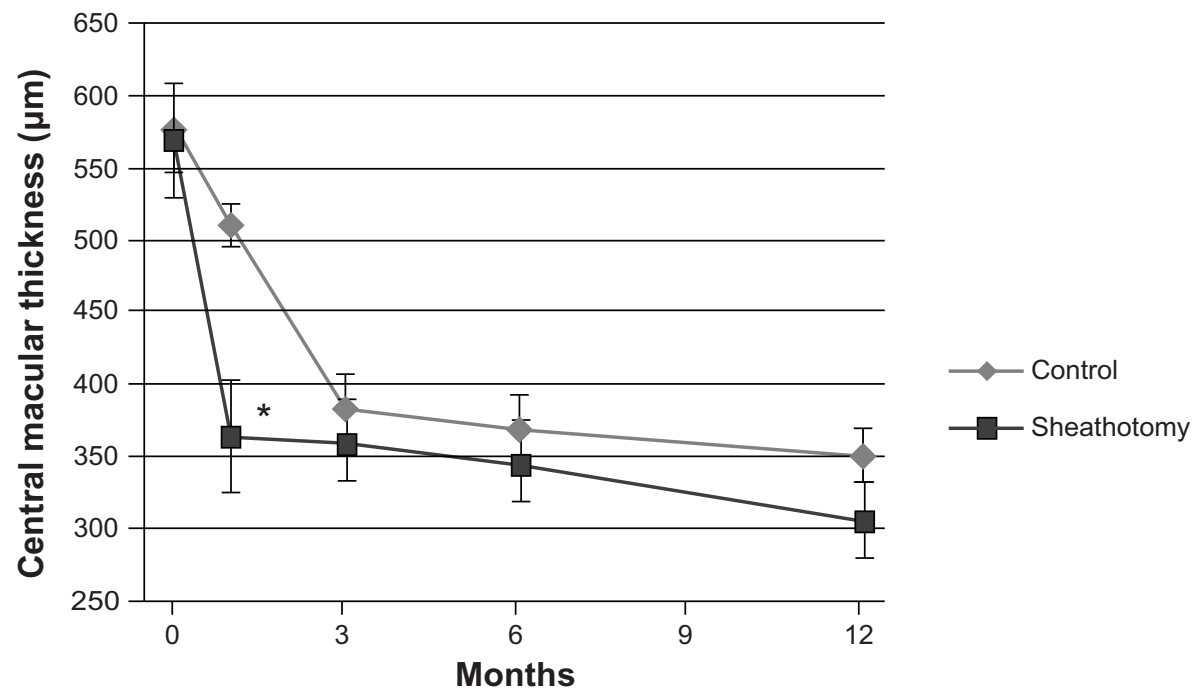

Figure 3 Changes in mean central macular thickness determined by optical coherence tomography. $* p<0.05$, Mann-Whitney $U$ test. Abbreviation: BCVA, best-corrected visual acuity. 
Table 2 Multiple regression analysis of improvement of the visual acuity at 12 months

\begin{tabular}{|c|c|c|c|}
\hline $\begin{array}{l}\text { Independent } \\
\text { variables }\end{array}$ & $\begin{array}{l}\text { Partial regression } \\
\text { coefficient }\end{array}$ & $\begin{array}{l}\text { Standard } \\
\text { error }\end{array}$ & $P$-value \\
\hline Baseline BCVA & 0.549 & 0.103 & 0.000 \\
\hline Age & -0.012 & 0.004 & 0.002 \\
\hline Sheathotomy & 0.201 & 0.060 & 0.001 \\
\hline Duration of symptom & -0.007 & 0.003 & 0.015 \\
\hline
\end{tabular}

Abbreviation: BCVA, best corrected visual acuity.

analyses strengthen the evidence of the effect of arteriovenous sheathotomy for BRVO.

There are some treatments for macular edema due to BRVO besides arteriovenous sheathotomy. The Branch Vein Occlusion Study reported on the efficacy of grid laser photocoagulation for macular edema secondary to BRVO, and this treatment has become the standard treatment. ${ }^{1}$ Patients treated with laser photocoagulation showed a significant mean improvement of 1.33 Snellen lines compared with 0.23 lines in the control group. Intravitreal injection of triamcinolone acetonide has also been used to treat macular edema in BRVO. ${ }^{23-26}$ However, triamcinolone acetonide is a steroid, and some of the eyes had an increase in intraocular pressure and cataract formation. ${ }^{27,28}$ The Standard Care versus Corticosteroid for Retinal Vein Occlusion Study reported no significant difference in visual acuity at 12 months for the standard care group compared with the injection group, but the incidence of adverse events was higher in the injection group. ${ }^{29}$ The efficacy and safety of intravitreal ranibizumab and bevacizumab, both antivascular endothelial growth factor antibodies, in treating the macular edema associated with BRVO were also reported to be good. ${ }^{30,31}$ These agents are now used widely because of their favorable outcomes.

A prospective randomized multicenter trial demonstrated better visual outcomes in eyes after ranibizumab injections than control eyes with sham injections. The mean change in BCVA from the baseline letter score at 12 months was 18.3 in eyes injected with $0.5 \mathrm{mg}$ ranibizumab. $^{32}$ In our study, the mean change in BCVA from baseline was $0.42 \log$ MAR units at 12 months. Although the baseline characteristics were different in these studies, the effect of arteriovenous sheathotomy was comparable with that of ranibizumab injection for visual recovery at 12 months. However, the cost-benefit ratio of arteriovenous sheathotomy may be lower than that for ranibizumab injections..$^{33}$

There are limitations to our study. First, patients were not randomly assigned to the treatment groups. Second, combined cataract surgery and internal limiting membrane peeling might affect visual outcomes. However, multiple regression analysis showed that the correlation between visual improvement at 12 months and combined cataract surgery was not significant. Further study is required to exclude the effect of internal limiting membrane peeling. Third, the duration of symptoms was significantly longer in the sheathotomy group than in the control group due to the waiting time before surgery (2.0 \pm 1.3 months). Earlier treatment might have resulted in better visual outcomes. We are presently planning a prospective randomized multicenter study to confirm the efficacy of arteriovenous sheathotomy.

In conclusion, arteriovenous sheathotomy results in significantly better visual outcomes compared with the natural course of BRVO. A randomized controlled study comparing arteriovenous sheathotomy, grid laser photocoagulation, and anti-vascular endothelial growth factor therapy is required to determine which treatment is most efficacious.

\section{Disclosure}

The authors report no conflicts of interest in this work.

\section{References}

1. [No authors listed]. Argon laser photocoagulation for macular edema in branch vein occlusion. The Branch Vein Occlusion Study Group. Am J Ophthalmol. 1984;98:271-282.

2. Michels RG, Gass JD. The natural course of retinal branch vein obstruction. Trans Am Acad Ophthalmol Otolaryngol. 1974;78: OP166-OP177.

3. Mitchell P, Smith W, Chang A. Prevalence and associations of retinal vein occlusion in Australia. The Blue Mountains Eye Study. Arch Ophthalmol. 1996;114:1243-1247.

4. Weinberg D, Dodwell DG, Fern SA. Anatomy of arteriovenous crossings in branch retinal vein occlusion. Am J Ophthalmol. 1990;109: 298-302.

5. Frangieh GT, Green WR, Barraquer-Somers E, Finkelstein D. Histopathologic study of nine branch retinal vein occlusions. Arch Ophthalmol. 1982;100:1132-1140.

6. Kumar B, Yu DY, Morgan WH, Barry CJ, Constable IJ, McAllister IL. The distribution of angioarchitectural changes within the vicinity of the arteriovenous crossing in branch retinal vein occlusion. Ophthalmology. 1998;105:424-427.

7. Osterloh MD, Charles S. Surgical decompression of branch retinal vein occlusions. Arch Ophthalmol. 1988;106:1469-1471.

8. Opremcak EM, Bruce RA. Surgical decompression of branch retinal vein occlusion via arteriovenous crossing sheathotomy: a prospective review of 15 cases. Retina. 1999;19:1-5.

9. Shah GK, Sharma S, Fineman MS, Federman J, Brown MM, Brown GC. Arteriovenous adventitial sheathotomy for the treatment of macular edema associated with branch retinal vein occlusion. Am JOphthalmol. 2000;129:104-106.

10. Mester U, Dillinger P. Vitrectomy with arteriovenous decompression and internal limiting membrane dissection in branch retinal vein occlusion. Retina. 2002;22:740-746.

11. García-Arumí J, Martinez-Castillo V, Boixadera A, Blasco H, Corcostegui B. Management of macular edema in branch retinal vein occlusion with sheathotomy and recombinant tissue plasminogen activator. Retina. 2004;24:530-540. 
12. Fujii GY, de Juan E Jr, Humayun MS. Improvements after sheathotomy for branch retinal vein occlusion documented by optical coherence tomography and scanning laser ophthalmoscope. Ophthalmic Surg Lasers Imaging. 2003;34:49-52.

13. Han DP, Bennett SR, Williams DF, Dev S. Arteriovenous crossing dissection without separation of the retina vessels for treatment of branch retinal vein occlusion. Retina. 2003;23:145-151.

14. Mason J 3rd, Feist R, White M Jr, Swanner J, McGwin G Jr, Emond T. Sheathotomy to decompress branch retinal vein occlusion: a matched control study. Ophthalmology. 2004;111:540-545.

15. Yamaji H, Shiraga F, Tsuchida Y, Yamamoto Y, Ohtsuki H. Evaluation of arteriovenous crossing sheathotomy for branch retinal vein occlusion by fluorescein videoangiography and image analysis. Am J Ophthalmol. 2004;137:834-841.

16. Le Rouic JF, Bejjani RA, Rumen F, et al. Adventitial sheathotomy for decompression of recent onset branch retinal vein occlusion. Graefes Arch Clin Exp Ophthalmol. 2001;239:747-751.

17. Cahill MT, Kaiser PK, Sears JE, Fekrat S. The effect of arteriovenous sheathotomy on cystoid macular oedema secondary to branch retinal vein occlusion. Br J Ophthalmol. 2003;87:1329-1332.

18. Charbonnel J, Glacet-Bernard A, Korobelnik JF, et al. Management of branch retinal vein occlusion with vitrectomy and arteriovenous adventitial sheathotomy, the possible role of surgical posterior vitreous detachment. Graefes Arch Clin Exp Ophthalmol. 2004;242:223-228.

19. Fujimoto R, Ogino N, Kumagai K, Demizu S, Furukawa M. [The efficacy of arteriovenous adventitial sheathotomy for macular edema in branch retinal vein occlusion]. Nihon Ganka Gakkai Zasshi. 2004;108: 144-149. Japanese.

20. Yamamoto S, Saito W, Yagi F, Takeuchi S, Sato E, Mizunoya S. Vitrectomy with or without arteriovenous adventitial sheathotomy for macular edema associated with branch retinal vein occlusion. Am JOphthalmol. 2004;138:907-914.

21. Kumagai K, Furukawa M, Ogino N, Uemura A, Larson E. Long-term outcomes of vitrectomy with or without arteriovenous sheathotomy in branch retinal vein occlusion. Retina. 2007;27:49-54.

22. Oh IK, Kim S, Oh J, Huh K. Long-term visual outcome of arteriovenous adventitial sheathotomy on branch retinal vein occlusion induced macular edema. Korean J Ophthalmol. 2008;22:1-5.
23. Cekic $\mathrm{O}$, Chang $\mathrm{S}$, Tseng JJ, et al. Intravitreal triamcinolone injection for treatment of macular edema secondary to branch retinal vein occlusion. Retina. 2005;25:851-855.

24. Krepler K, Ergun E, Sacu S, et al. Intravitreal triamcinolone acetonide in patients with macular oedema due to branch retinal vein occlusion: a pilot study. Acta Ophthalmol Scand. 2005;83:600-604.

25. Chen SD, Sundaram V, Lochhead J, Patel CK. Intravitreal triamcinolone for the treatment of ischemic macular edema associated with branch retinal vein occlusion. Am J Ophthalmol. 2006;141:876-883.

26. Ozkiris A, Evereklioglu C, Erkilic K, Dogan H. Intravitreal triamcinolone acetonide for treatment of persistent macular oedema in branch retinal vein occlusion. Eye (Lond). 2006;20:13-17.

27. Jaissle GB, Szurman P, Bartz-Schmidt KU. [Ocular side effects and complications of intravitreal triamcinolone acetonide injection]. Ophthalmologe. 2004;101:121-128. German.

28. Thompson JT. Cataract formation and other complications of intravitreal triamcinolone for macular edema. Am J Ophthalmol. 2006;141: 629-637.

29. Scott IU, Ip MS, VanVeldhuisen PC, et al. A randomized trial comparing the efficacy and safety of intravitreal triamcinolone with standard care to treat vision loss associated with macular edema secondary to branch retinal vein occlusion: the Standard Care vs Corticosteroid for Retinal Vein Occlusion (SCORE) study report 6. Arch Ophthalmol. 2009;127:1115-1128.

30. Rabena MD, Pieramici DJ, Castellarin AA, Nasir MA, Avery RL. Intravitreal bevacizumab (Avastin) in the treatment of macular edema secondary to branch retinal vein occlusion. Retina. 2007;27:419-425.

31. Moradian S, Faghihi H, Sadeghi B, et al. Intravitreal bevacizumab vs sham treatment in acute branch retinal vein occlusion with macular edema: results at 3 months (Report 1). Graefes Arch Clin Exp Ophthalmol. 2011;249:193-200.

32. Brown DM, Campochiaro PA, Bhisitkul RB, et al. Sustained benefits from ranibizumab for macular edema following branch retinal vein occlusion: 12-month outcomes of a phase III study. Ophthalmology. 2011;118:1594-1602.

33. Smiddy WE. Economic considerations of macular edema therapies. Ophthalmology. 2011;118:1827-1833.
Clinical Ophthalmology

\section{Publish your work in this journal}

Clinical Ophthalmology is an international, peer-reviewed journal covering all subspecialties within ophthalmology. Key topics include: Optometry; Visual science; Pharmacology and drug therapy in eye diseases; Basic Sciences; Primary and Secondary eye care; Patient Safety and Quality of Care Improvements. This journal is indexed on
Dovepress

PubMed Central and CAS, and is the official journal of The Society of Clinical Ophthalmology (SCO). The manuscript management system is completely online and includes a very quick and fair peer-review system, which is all easy to use. Visit http://www.dovepress.com/ testimonials.php to read real quotes from published authors. 